\title{
Commonplace
}

\section{A Commentary on Textbooks in the Library Collection}

Scarlet Galvan ${ }^{1}$, Cara Cadena ${ }^{2}$

${ }^{1}$ Collection Strategist, GVSU Libraries, ${ }^{2}$ Head of Collections and Digital Scholarship, GVSU Libraries

Published on: Aug 03, 2020

DOI: $10.21428 / 6 \mathrm{ffd} 8432.55114004$

License: Creative Commons Attribution 4.0 International License (CC-BY 4.0). 


\section{The Problem}

Academic libraries face unprecedented demand for digital access to textbooks. While they've tried to meet this need, these efforts are complicated by some publishers who do not provide institutional purchasing options. Students and their professors are then responsible for the cost of the book and the library is seen as a barrier to information rather than a collaborator. COVID-19 accelerated the erosion of buying power in the traditional scholarly communications environment. Subscription costs have been unsustainable for many years, taking a larger percentage of the acquisitions budget to maintain a more homogenized, less inclusive, and less responsive collection as a result. The library essentially pays more for less coverage each year. As funding to higher education has been under threat since the 1990s (and academic libraries since their inception) the relationship between equity and access appears, for instance, in countless surveys that show students avoid courses with expensive textbooks.

\section{The Price of Innovation}

Ensuring authors have the tools and skills to contribute openly while also building institution-wide support for open publishing practices will enable librarians to resist paying textbook companies. The recent lawsuit brought against the Internet Archive by four major publishers highlights the disconnect between publishers, librarians, and users. Converting print textbooks we've already paid for has mixed results; it's precarious and digitized PDF versions of outdated books are less than ideal for users.

Librarians and university administrators agree that the library should be responsive to user needs and the collection should enhance curricula, yet in practice we see these values at odds with promotion criteria that bolsters the revenue of publishers. Our home institutions have work to do as well: tenure and promotion guidelines explicitly recognizing open and equitable access to scholarship can realign these shared values.

\section{Conclusion: What's Possible}

We're about to enter a fall semester that will not be campus as usual with masks. To fully support digital learning, libraries need the ability to offer resources in flexible formats. Providing access to e-textbooks is one step towards leveling the uneven playing field in knowledge production. 
University of Guelph Libraries' statement $\underline{1}$ explaining these issues has been adopted by institutions throughout the United States and Canada, including ours at Grand Valley State University Libraries. It articulates a tension between our professions, that libraries and content providers shouldn't have adversarial relationships. These statements are sometimes called brave or fiery, and it's striking to us that describing conditions of access and limitations on academic libraries' ability to meet extraordinary needs would be characterized as anything other than everyday advocacy.

This is not a library problem. This is an industry problem that impacts everyone in higher education: students, advocates in support and success roles, and teaching faculty. It has implications for institutional research output, grant funding, and emphasizes the branding of scholarship, the container it is disseminated within, rather than the content itself. Authors are pressured to maintain a system of scholarly communication that does not serve them, and incentivizes metrics which may not reflect real-world impact for tenure and promotion. These value systems are inherited, codified by graduate programs, industry rankings, and a framework that incorrectly situates librarians as gatekeepers between content providers and patrons.

Our futures are inextricably connected, and this moment only accelerates discussions throughout librarianship and publishing of how to reimagine that shared future in more equitable terms.

\section{Footnotes}

1. https://www.lib.uoguelph.ca/news/commercial-textbooks-present-challengesvirtual-environment $\leftrightarrows$ 